\title{
Riscos corporativos: um estudo de caso em uma empresa prestadora de serviços
}

\author{
Cassiane Chais 1 \\ Daniel Hank Miri² \\ Juliana Matte ${ }^{3}$ \\ Luana Folchini da Costa ${ }^{4}$ \\ Paula Patrícia Ganzer ${ }^{5}$ \\ Pelayo Munhoz Olea ${ }^{6}$ \\ Vanessa de Campos Machado ${ }^{7}$
}

\begin{abstract}
Resumo: Os riscos sempre estiveram presentes nos negócios, mas quando não são gerenciados, refletem na economia e na sociedade, visto que o mercado se adapta aos ciclos de eventos financeiros. A partir de 2007, houve uma crescente busca por ferramentas de gestão voltadas à prevenção de riscos, capazes de garantir a continuidade do negócio. Por isso, o objetivo deste artigo foi analisar a implantação de um sistema de gestão para administrar os riscos envolvidos no negócio. A pesquisa possui abordagem qualitativa, através de um estudo de caso único e exploratório. Foram realizadas entrevistas individuais em profundidade por meio de um roteiro de entrevista semiestruturado, aplicadas aos gestores envolvidos no processo de implementação de um
\end{abstract}

${ }^{1}$ Doutora em Administração, PROSUC / CAPES, pela Universidade de Caxias do Sul, Mestre em Administração pela Universidade de Caxias do Sul, graduação em Secretariado Executivo pela Universidade de Passo Fundo, com bolsa PROUNI, cassichais@ gmail.com.

${ }^{2}$ Mestre em Administração no Programa de Pós-Graduação em Administração - PPGA da Universidade de Caxias do Sul - UCS na linha de Inovação e Competitividade com bolsa PROSUC / CAPES Modalidade I, Graduação em Administração pela Universidade de Caxias do Sul e formação no curso superior de duração em Gestão de Pessoas pela Universidade de Caxias do Sul, danielmirid@gmail.com.

${ }^{3}$ Doutoranda em Administração no Programa de Pós-Graduação em Administração - PPGA da Universidade de Caxias do Sul - UCS com bolsa FAPERGS / CAPES. Mestre em Administração no Programa de PósGraduação em Administração - PPGA da Universidade de Caxias do Sul - UCS. MBA em Gestão Comercial pela Fundação Getúlio Vargas - FGV. Graduada em Administração com ênfase em Marketing pela Universidade Federal do Rio Grande do Sul - UFRGS. Integrante do Grupo de Pesquisa Núcleo de Inovação, Empreendedorismo e Sustentabilidade - NIES, ju.cxs1@gmail.com.

${ }^{4}$ Doutorado em Administração pela Universidade de Caxias do Sul (UCS) em andamento. Mestre em Administração pela Universidade de Caxias do Sul (UCS), Graduada em Psicologia pela Universidade de Caxias do Sul (UCS), luana.folchini@gmail.com.

5 Pós-Doutora em Administração pela Universidade de Caxias do Sul, UCS, Brasil. Doutorado em Administração pela Pontifícia Universidade Católica do Rio Grande do Sul, PUCRS, Brasil e pela Universidade de Caxias do Sul, UCS, Brasil. Mestrado em Administração pela Universidade de Caxias do Sul, UCS, Brasil. Graduação em Administração pelo Centro de Ensino Superior Cenecista de Farroupilha, CESF, Brasil,ganzer.paula@gmail.com.

${ }^{6}$ Pós-Doutorado em Gestão Ambiental pela Universidad de Extremadura, UEX, Espanha, Doutorado em Administração e Direção de Empresas pela Universitat Politècnica de Catalunya, ETSEIB/UPC, Espanha, Mestrado em Engenharia de Fabricação de Papel pela Universitat Politècnica de Catalunya, ETSEIAT/UPC, Espanha. Graduação em Administração de Empresas pela Pontifícia Universidade Católica do Rio Grande do Sul, PUC/RS e Graduação em Engenharia Mecânica pela Pontifícia Universidade Católica do Rio Grande do Sul, PUC/RS, pelayo.olea@gmail.com.

${ }^{7}$ Mestrado em Administração pela Universidade de Caxias do Sul, Graduação em Engenharia de Produção pela Universidade de Caxias do Sul, com período sanduíche na Miami University, Ohio, vcmachado@ucs.br. 
sistema de gestão de riscos na empresa estudada. Após análise de conteúdo das entrevistas, como principal resultado, foi identificado que houve mudanças na gestão da organização, que adotou uma postura mais preventiva e estratégica para evitar perdas, e essas mudanças trouxeram resultados positivos à gestão da organização.

Palavras-chave: Gestão de Riscos; Implementação; Estratégia.

\title{
Corporate Risk: A Case Study in a Service Provider
}

\begin{abstract}
Risks have always been present in business, but when they are not managed, they reflect in the economy and society, as the market adapts to the cycles of financial events. As of 2007, there was a growing search for management tools aimed at risk prevention, capable of ensuring business continuity. Therefore, the objective of this article was to analyze the implementation of a management system to manage the risks involved in the business. The research has a qualitative approach, through a unique exploratory case study. Individual interviews were conducted in depth through a semistructured interview script, which were carried out with the managers involved in the process of implementing a risk management system in the company studied. After analyzing the content of the interviews, as main results, it was identified that there were changes in the management of the organization, which adopted a more preventive and strategic posture to avoid losses and these changes brought positive results to the management of the organization.
\end{abstract}

Keywords: Risk Management; Implementation; Strategy.

\section{Riesgos corporativos: un estudio de caso en un proveedor de servicios}

Resumen: Los riesgos siempre han estado presentes en los negocios, pero cuando no se gestionan, se reflejan en la economía y la sociedad, ya que el mercado se adapta a los ciclos de eventos financieros. A partir de 2007, existe una creciente búsqueda de herramientas de gestión orientadas a la prevención de riesgos, capaces de asegurar la continuidad del negocio. Por tanto, el objetivo de este artículo fue analizar la implantación de un sistema de gestión para gestionar los riesgos implicados en el negocio. La investigación tiene un enfoque cualitativo, a través de un estudio de caso único y exploratorio. Se realizaron entrevistas individuales en profundidad a través de un guión de entrevista semiestructurado, las cuales se realizaron con los gerentes involucrados en el proceso de implementación de un sistema de gestión de riesgos en la empresa estudiada. Luego de analizar el contenido de las entrevistas, como principales resultados, se identificó que hubo cambios en la gestión de la organización, que adoptó una postura más preventiva y estratégica para evitar pérdidas y estos cambios trajeron resultados positivos a la gestión de la organización.

Palabras clave: Gestión de riesgos; Implementación; Estrategia.

\section{Introdução}

Os riscos corporativos são as ocorrências e possíveis ocorrências que possam limitar a organização e as partes envolvidas no negócio de ganharem dinheiro e reconhecimento profissional. Gerir riscos possibilita às empresas se prepararem estrategicamente a possíveis efeitos indesejáveis em que o negócio esteja inserido, permitindo uma tomada de decisão mais assertiva. Os riscos corporativos estão presentes em todos os tipos de segmentos empresariais, porém é possível a mitigação dos mesmos para minimizar perdas (BARALDI, 2010). 
A gestão de riscos oferece suporte à criação de valor, permitindo que a equipe de gerenciamento sênior da unidade de negócios lide de maneira eficaz com possíveis eventos futuros que possam gerar incerteza para a unidade de negócios e responder de maneira a reduzir a probabilidade de queda e aumentar a vantagem da unidade de negócios, o desempenho financeiro e a imagem de reputação (CHOO; GOH, 2015).

A norma de gestão de sistemas de qualidade afirma que risco é o efeito da incerteza sobre um resultado planejado, sendo esses eventos capazes de afetar os propósitos da organização. Essa norma aborda a necessidade de se estabelecer um propósito com pensamento baseado em riscos, para: identificar, monitorar, medir e mitigar os possíveis riscos intrínsecos aos seus processos, visando minimizar os impactos negativos (ABNT ISO 9001, 2015). Por sua vez, a ISO 31000 pode ser considerada como um importante modelo para ser usado na eficácia do gerenciamento de risco das empresas (DIAS, 2017).

O objetivo do artigo foi analisar a implantação de um sistema de gestão para administrar os riscos envolvidos no negócio. Para isso, a pesquisa contou com uma abordagem qualitativa, com entrevistas individuais em profundidade com gestores que estavam envolvidos no processo de implementação de um sistema de gestão de riscos na empresa Metaltecss Revestimento de Metais Ltda.

A estrutura do artigo possui a revisão da literatura com os riscos corporativos, gerenciamento de riscos com as suas ferramentas, seguida da metodologia, resultados da pesquisa qualitativa e considerações finais.

\section{Revisão da Literatura}

\subsection{Riscos Corporativos}

A tomada de decisão nas atividades de uma organização possui seus riscos e o gestor deve considerá-los de tal forma a ser preventivo, podendo este ocorrer ou não. Deve-se considerar que decisões de alto risco possuem propensão ao retorno elevado e decisões de baixo risco apresentam baixo retorno. Analisando as técnicas de avaliação de riscos, pressupõem-se novos paradigmas: o que antes era controlar e tratar um risco já conhecido e voltado às origens financeiras, hoje se trabalha na previsão e prevenção de um risco em potencial de qualquer área corporativa (BERGAMINI, 2015).

As incertezas enfrentadas pelas empresas sugerem duas vertentes: a de riscos e a de 
oportunidades, sendo que caberá ao gestor determinar a forma de gerenciamento para cada vertente, a fim de eliminar ou mitigar o risco para evitar perdas, e a de gerar valor através das oportunidades. Consequentemente, a identificação de riscos é uma atividade fundamental a qualquer organização, uma vez que a ocorrência dos riscos pode impedir o alcance das metas e objetivos (MASSAINI et al., 2017). Assim, as metas e os objetivos da organização devem ser alicerçados às estratégias para serem alcançadas e serem direcionadas para os riscos inerentes que as compõem, possibilitando a obtenção de um retorno superior (BRASILIANO, 2016).

Por fim, com relação à prevenção, as empresas consideram mais importante esclarecer os riscos e como eles afetam a empresa, em vez de informações de divulgação sobre políticas que foram usadas para lidar com riscos (GULKO et al., 2017).

\subsection{Gerenciamento de Riscos}

Controle interno é um processo sustentado pelos preceitos de governança corporativa e seus integrantes, criado para garantir o atendimento dos objetivos. Os fundamentos que fazem parte do contexto de controle interno são: deve ser voltado para atingir os objetivos; ser um processo de contínua melhoria para a organização; ser uma prática conduzida por pessoas de todos os níveis hierárquicos; ser capaz de prover segurança do negócio à alta administração e ser flexível à identidade da organização e seus processos diretos e intermediários (COSO, 2013).

A evolução das práticas de governança corporativa promoveu a adoção de um gerenciamento de riscos corporativos nas empresas, dada a necessidade de gerenciar de forma assertiva as oportunidades e as ameaças do negócio, visando a obter o melhor retorno aos acionistas. Dessa forma, a gestão de riscos se torna uma ferramenta de gestão capaz de aumentar as chances de atingir os resultados pretendidos (PRADO et al., 2014).

O processo de gerenciamento de riscos corporativos deve compreender uma sistemática eficaz de controle interno, a fim de promover maior garantia para o atendimento dos objetivos da organização. O controle interno atribuído, por si só, não garante a eficácia do sistema como um todo. É necessário que a organização esteja ciente de suas limitações para relacionar controles que minimizem seus pontos fracos (BRASILIANO, 2016).

O gerenciamento de riscos é cada vez mais visto como um meio de melhorar a probabilidade de sucesso em projetos organizacionais complexos. O gerenciamento de risco 
é parte da tomada de decisão; ao encontrar o risco, reforça-se a ideia de que o gerenciamento de riscos deve ser uma parte do processo completo de gerenciamento de projetos, além de agir como uma ferramenta para tomada de decisão estruturada e cuidadosa (OLECHOWSKI et al., 2016).

\subsection{Ferramentas de Gerenciamento de Riscos}

A ISO 9001 é a norma internacional que especifica requisitos para sistemas de gerenciamento de qualidade. As organizações implementam os requisitos do padrão para demonstrar a capacidade de fornecer consistentemente produtos e serviços que atendam aos requisitos do cliente e regulamentares.

A ISO 9001, na sua mais recente revisão, em 2015, trouxe como principal mudança o foco baseado em riscos e a necessidade que as empresas possuem de ampliar sua gestão de negócios, agregando ao planejamento estratégico o gerenciamento de riscos, determinando ações de gestão para cobrir fatores indesejáveis. Outro ponto importante trazido pela nova estrutura desta norma é que as empresas devem contemplar em seu gerenciamento de riscos as "partes interessadas", que constituem os grupos ou os indivíduos que apresentam um potencial de impactar nos negócios da empresa (LOPES, 2016).

A norma ISO 9001 tem desempenhado um papel importante e um dos mais relevantes na percepção da qualidade e compreensão da garantia de qualidade e gestão da qualidade nos últimos trinta anos. A revisão de 2015 visou a garantir que a ISO 9001 continue a se adaptar aos ambientes em mudança em que as organizações operam e inclua especialmente o 'contexto' da organização, reestruturação das informações, pensamento baseado em risco para melhorar a aplicação da abordagem de processo, melhor aplicabilidade para serviços e aumento dos requisitos de liderança (MEDIĆ et al., 2016).

Em 2009, a ISO (International Organization for Standardization) lançou a norma ISO 31000, que tem o propósito de integrar um sistema de gestão de riscos aos processos de qualquer tipo de organização. A norma tem a finalidade de conformar padrões, regulamentações e outros frameworks relacionados à gestão de riscos, em uma ferramenta para orientar as empresas a implementar o método para gerir e tratar as incertezas inerentes a qualquer negócio (BRASILIANO, 2016).

A estrutura de gerenciamento de riscos corporativos da ISO 31000:2009 determina que não é um tamanho único para todos. Em vez disso, as organizações que desejam 
adaptarem essa estrutura precisam se adequar, mas não há indicações de como as organizações podem fazê-lo (CHOO; GOH, 2015). Como essa norma não se limita ao tipo e ao contexto de organização, a mesma se apresenta de forma e princípios abrangentes, e se estende a toda organização, suas áreas e níveis, provendo auxílio na tomada de decisões para tratar qualquer tipo de risco existente no negócio (FERRO, 2015).

O COSO é uma organização não governamental, criada nos Estados Unidos, em 1985, que nasceu com o propósito de determinar controles internos, voltados a prevenir e evitar fraudes contábeis nas empresas. O COSO teve sua primeira edição publicada em 1992 e ficou conhecido mundialmente por ser uma ferramenta de modelo orientado a desenvolver, implementar, conduzir e validar sua eficácia para um controle de gerenciamento de riscos corporativos (BRASILIANO, 2016).

Em 2017, o COSO emitiu uma estrutura de ERM atualizada, Gerenciamento de Riscos Corporativos - Integração com Estratégia e Desempenho. A estrutura revisada define o ERM como a cultura, os recursos e as práticas, ligados com a estratégia e a execução, que as empresas confiam para gerenciar riscos na geração, preservação e obtenção de valor. A orientação atualizada do COSO inclui cinco componentes e vinte princípios destinados a ajudar as organizações a navegar em um ambiente complexo de governança, risco e conformidade (WRIGHT, 2018).

Os princípios do COSO são fundamentais para a obtenção de qualquer auditoria, principalmente no que diz respeito ao gerenciamentos de riscos (DIAS, 2017), pois são usados pela gerência para melhorar a capacidade de uma organização de administrar incertezas e considerar quanto risco aceitar quando se esforça para aumentar as partes interessadas (WRIGHT, 2018).

\section{Metodologia}

A pesquisa possui uma abordagem qualitativa e exploratória que pretende, através da interpretação de fenômenos, alcançar os objetivos propostos neste trabalho (FLYCK, 2009). A estratégia foi o estudo de caso único (YIN, 2015), na empresa Metaltecss Revestimento de Metais Ltda. A empresa está localizada em Caxias do Sul, no estado do Rio Grande do Sul, atuante no mercado desde 1984, ao prestar serviços de pintura em peças. Pertencente ao setor metalmecânico desta cidade, atua em um nicho de mercado diversificado. Os principais segmentos cobertos pelos seus serviços são as indústrias automobilística, agrícola, de 
implementos e da construção civil.

A Metaltecss está enquadrada como empresa de médio porte, possui atualmente 100 funcionários e sua instalação compreende cerca de seis mil metros de área construída. Dentre seus serviços, estão a pintura a pó e pintura (revestimento) e-coat. A empresa possui seu sistema de gestão de qualidade certificado na norma ISO 9001 desde 2002, a qual na sua nova revisão, em 2015, exigiu que as organizações certificadas implementassem um processo gerencial de riscos, sendo esse o tema deste trabalho.

O processo de coleta de dados do trabalho foi por meio de entrevistas individuais em profundidade, com roteiro semiestruturado, adaptado de Ferro (2015), composto por 15 perguntas, que analisaram os aspectos relativos ao processo de gestão de riscos na empresa estudada.

Foram realizadas, no mês de setembro de 2017, quatro entrevistas com gestores da empresa, que geraram um tempo total de gravação de 2 horas e 56 minutos e uma transcrição de 19 páginas. A escolha dos participantes se deu pelo grau de envolvimento de cada entrevistado na implantação da gestão de riscos, e que pudesse responder ao roteiro de entrevista. A Entrevistada 1 possui a função de Analista de Processos, responsável pelo processo técnico da organização. A Entrevistada 2 é Analista de Recursos Humanos e responsável pela gestão de pessoas. A Entrevistada 3, também Analista de Processos, é responsável pelo desenvolvimento de processos e pelo processo de manutenção da organização. Por fim, o Entrevistado 4 é Consultor na área de gestão de qualidade para empresas certificadas e realiza a implantação da gestão de riscos em empresas.

Para análise de dados, foi realizada a análise de conteúdo (FLICK, 2009) com auxílio do software NVivo®11.

\section{Resultados}

\subsection{Importância da gestão de riscos segundo os entrevistados}

Buscou-se analisar a opinião dos entrevistados a respeito da importância de se ter uma área de gestão de riscos na empresa. Nas respostas dos entrevistados, notou-se concordância relativa à importância da gestão de riscos para a continuidade do negócio e evitar perdas, corroborando com os autores citados anteriormente. A Entrevistada 1 ressaltou que "no cenário atual, momentos de instabilidade política e macroeconômica, a gestão de 
riscos é fundamental e estratégica para manter o equilíbrio através de uma análise global de riscos".

A Entrevistada 2 comentou que o processo é fundamental para a continuidade do negócio: "Percebi, neste trabalho, que o grupo gestor passa a visualizar o que é mais importante e fundamental para a continuidade da empresa, pois passamos a gerir os riscos, visando a minimizá-los e podermos, dessa forma, evitar ou reduzir perdas”.

A Entrevistada 3 falou que a gestão de riscos é uma importante ferramenta estratégica e disse: "É uma área que tem uma importância de nível estratégico na empresa, que tem poder de influenciar os direcionamentos estratégicos do negócio”. O Entrevistado 4 argumentou sobre as relações de partes interessadas com a gestão de riscos da empresa:

\footnotetext{
Vejo a gestão de riscos como principal aliada à prevenção de perdas, pois à medida que as relações comerciais entre fornecedores, clientes e consumidores se alteram e se complementam com a ampliação da legislação e proteção ao consumidor, a área de gestão de riscos assume um papel importante, inclusive na prevenção de perdas com garantias, como a de responsabilidade civil ou por recall, pois dá suporte para a organização a se preparar a riscos potenciais em que o negócio esteja inserido.
}

Ainda sobre a percepção da importância de um sistema de gestão de riscos, buscouse entender como ocorreu o processo de desenvolvimento, para saber quais foram os aspectos motivadores que levaram a implementação de uma área de gestão de riscos na empresa.

A norma ABNT ISO 31000 (2009) menciona que a maior parte das organizações não possui um sistema para tratar os riscos que podem resultar em perdas para o negócio. A ISO 9001 trouxe, em 2015, a necessidade de um pensamento baseado em riscos, tornando obrigatória a gestão de riscos para empresas certificadas (LOPES, 2016). As exigências de mercado são uma das principais motivações para a adoção de um sistema preventivo de falhas, visando a aperfeiçoar suas estratégias no mercado e sobrevivência do negócio (FERRO, 2015).

Os entrevistados afirmaram que o principal fator motivacional para buscar implementar a gestão de riscos foi a exigência da norma ISO 9001, ao qual a empresa é certificada. Porém, também foram mencionadas exigências de clientes, o que é suportado pelo referencial teórico. A Entrevistada 1 comentou: "A gestão de riscos foi recém-criada, em função da ISO 9001:2015, que abrange um projeto voltado para gestão de riscos [...] todos os gestores da empresa foram convocados no desenvolvimento do projeto". 
A Entrevistada 2 disse: "O que nos motivou a começar este trabalho foi porque é uma nova diretriz da nova versão da ISO 9001, e tivemos que nos adequar para obter a certificação [...] mas também tem os nossos clientes que já estão exigindo coisas relacionadas a riscos do negócio". Os demais entrevistados também mencionaram que a exigência da certificadora foi o principal motivo para desenvolver gestão de riscos na empresa. A importância de um gerenciamento de riscos sofisticado e maduro que não se sustenta por si só, mas está bem integrado ao restante do projeto e da organização (OLECHOWSKI et al., 2016).

\subsection{Linguagem comum ao risco}

Foi questionado aos entrevistados se eles compreendiam a definição de riscos adotada pela empresa, que tipo de riscos eram considerados e se era formalizada dentro da empresa, buscando entender se a gestão era disseminada por toda a organização e se havia uma linguagem comum.

Houve concordância entre os entrevistados ao falar das questões abordadas, demonstrando que a gestão está aderente e que é de conhecimento dos envolvidos, aderindo ao referencial teórico. Foi comentado sobre o envolvimento das pessoas no levantamento dos riscos, que o processo está documentado e que é de conhecimento das pessoas da organização. A Entrevistada 1 ressaltou:

As definições para risco adotadas foram tabuladas em planilha desenvolvida para estudo de caso, contendo partes envolvidas, processo e ambiente afetado. Também foi estudado qual o impacto, gravidade de cada risco. [...] A planilha foi tratada e apresentada a todo pessoal administrativo e para Direção da Empresa. Também está formalizada e é possível acessar em via eletrônica.

A Entrevistada 2 falou como foram levantados os potenciais riscos dos processos e de como foi documentada a gestão:

\footnotetext{
Nós, o grupo gestor, mapeamos todos os processos [...] fizemos um brainstorming dos riscos que achávamos que tinham em cada processo, daí como tínhamos dados e históricos ficou mais fácil de selecionar os principais riscos potenciais [...] Como eu disse, documentamos isso, para as partes interessadas fizemos uma classificação do contexto em que estavam inseridas, temos uma planilha de gestão de riscos e de oportunidades também [...] fica disponível para todos os gestores, e em reuniões discutimos qualquer necessidade de alterações, para manter os documentos vivos.
} 
A Entrevistada 3 falou sobre a definição de riscos existente na empresa, também fez uma abordagem de como está constituído o processo de gestão:

\begin{abstract}
A definição adotada para os riscos é exatamente como o seu próprio nome diz: é qualquer evento que ofereça alguma influência negativa para o negócio. Seja ele de maior ou menor impacto. [...] os riscos são avaliados pela equipe e pontuados conforme o conhecimento de cada um, para que ao final dessa pontuação seja analisada a necessidade de tomar ações para eliminar ou minimizar esses riscos, monitorar os mesmos ou simplesmente ignorá-los por entender que os mesmos não oferecem ameaça para o negócio. [...] formalização é um procedimento do sistema de gestão que tem como objetivo orientar como é feita essa gestão.
\end{abstract}

Foi colocado pelo Entrevistado 4 o conceito de risco e a da obrigatoriedade imposta pela norma de certificação de documentar o processo de gestão de riscos:

É de conhecimento geral dos colaboradores o conceito de risco adotado pelas normas de sistema de gestão da qualidade que consiste em - risco é o efeito indesejável [...] para atendimento aos requisitos da norma ISO 9001, foi elaborado um procedimento para a gestão de riscos o qual orienta todas as atividades da gestão de riscos.

A norma ISO 9001 conduz a revisão da administração em intervalos planejados ou a realização de auditorias internas em intervalos planejados, que ainda não estão estritamente definidos (MEDIĆ et al., 2016).

\title{
4.3 Classificação dos riscos e responsabilidades
}

Esta seção buscou entender quais foram os critérios adotados para classificar os riscos do negócio e se as responsabilidades atribuídas para as atividades de gestão de riscos possuíam qualificação e habilidades para lidarem com este processo, bem como a estruturação que foi dada aos processos para receber a gestão de riscos.

Quanto às responsabilidades na gestão de riscos, a ABNT ISO 31000 (2009) afirmou que a gestão de riscos deve ser um processo integrante de todos os processos da empresa e de responsabilidades da administração. A ABNT ISO 9001 (2015) abordou que as organizações devem planejar e implementar ações para cobrir riscos e oportunidades de acordo com o contexto e objetivos em que estejam inseridas e alinhado ao direcionamento estratégico, ampliando sua gestão de negócios.

Nas respostas dadas pelos entrevistados, é possível verificar que houve uma classificação de riscos. Observa-se, pelas respostas, que esse processo ocorreu de forma 
empírica e com base no conhecimento dos gestores envolvidos no processo. A Entrevistada 1 informou como ocorreu a qualificação das pessoas responsáveis e a análise dos ambientes interno e externo:

\begin{abstract}
Está tudo documentado no plano de análise de riscos. As pessoas responsáveis são gestores com larga experiência internamente e também em empresas externas, possuem formação mínima em terceiro grau [...] Houve treinamentos externos e tem uma consultoria para nos qualificar para este trabalho [...] Há reuniões periódicas, onde os gestores participam e tratam do andamento das ações do plano de mitigação. Estas atividades foram mapeadas através das partes interessadas, internas ou externas, os processos e os ambientes afetados.
\end{abstract}

A Entrevistada 2 abordou o processo de qualificação do pessoal envolvido e as responsabilidades:

\begin{abstract}
As pessoas que foram envolvidas na implementação da gestão de riscos são os gestores de processos, os dois gerentes de vendas, o coordenador de planejamento de produção, dois analistas de processos, a analista da qualidade, eu, que sou analista de RH, e também a direção. Todos possuem formação acadêmica ou estão concluindo uma graduação, e possuem competência e habilidades para desenvolver este trabalho, pois possuem experiência nas áreas específicas e a maioria já está há bastante tempo na empresa, o que facilita o trabalho, pois conhecem bem o negócio da empresa, e por isso não tivemos dificuldades em definir e classificar os riscos de cada processo. As atividades são distribuídas entre o comitê, de acordo com o conhecimento e a área de cada um, os riscos que foram definidos nos mapas de processo, são de responsabilidade do gestor daquela área, já os riscos mais estratégicos são geridos pelo SGQ e a direção.
\end{abstract}

O Entrevistado 4 teve uma colocação mais abrangente, falando da classificação dos riscos, competências necessárias para gerir os mesmos, de como está estruturado o sistema, bem como da relação do direcionamento estratégico da empresa aos riscos. A gestão de riscos é tudo sobre estratégia e desempenho. Construir as melhores decisões na gestão de riscos é parte integrante da tomada de decisões (ANDERSON, 2017), como pôde ser considerado também nas entrevistas. Ainda, a qualidade mais alta do gerenciamento de riscos corporativos está associada a menor restrição de recursos, melhor governança corporativa e melhor desempenho contábil, visando à relevância do propósito da empresa (KAYA, 2018).

\title{
4.4 Direcionamento estratégico alinhado à gestão de riscos
}

A gestão de riscos deve estar alinhada aos objetivos e contexto da organização, com ações que cubram os potenciais riscos do negócio, fornecendo condições para melhorar os 
resultados da empresa. Deve-se promover uma gestão para possíveis eventos indesejáveis, identificando e classificando os riscos que afetem negativamente os objetivos da organização, esperando ter o melhor retorno esperado (BRASILIANO, 2016).

Nas entrevistas realizadas, foi possível entender que a empresa possui um direcionamento estratégico e que este está coberto pelo plano de gestão de riscos. A Entrevistada 3 explicou como os resultados foram avaliados e monitorados e como o desempenho é correlacionado com a gestão de riscos e os objetivos da organização:

Os objetivos e metas da empresa norteiam um direcionamento estratégico que é realizado uma vez por ano pelo grupo gestor. Com esse direcionamento estratégico e metas, o grupo de gestão de riscos entende os objetivos da empresa e desta forma direciona a mensuração, classificação dos riscos e implantação de ações.

O Entrevistado 4 corroborou, afirmando que os resultados são monitorados e avaliados quanto aos riscos potenciais, "os objetivos estão correlacionados com os indicadores de desempenho da organização, que também são utilizados para monitoramento dos riscos e oportunidades identificadas pela empresa" [...]. A adesão aos princípios de gestão de risco em alto nível é considerada um fator significativo no melhor alcance de custos, cronograma, metas técnicas e de clientes, além de alcançar uma execução mais estável do projeto (OLECHOWSKI et al., 2016).

\subsection{Análise dos contextos externos e internos}

Esta parte da entrevista verificou se a empresa realizou a análise dos ambientes interno e externo da organização para identificar os riscos de partes interessadas. A ABNT ISO 31000 (2009) mostra que essa análise é necessária para identificar e classificar as fontes de riscos.

Nas respostas dadas pelos quatro entrevistados, foi possível compreender como se deu o processo de avaliação dos ambientes interno e externo e que está de acordo com as normas referenciadas. A Entrevistada 1 falou da análise externa em relação às exigências de mercado e de cada segmento dos clientes:

Os fatores que influenciaram o ambiente interno e externo foram identificados através da importância no atendimento às normativas de cada tipo de negócios que a empresa fornece: montadoras automotivas, agrícola, arquitetônico, moveleiro e refrigeração. Sendo cada um destes um tipo de exigência [...] O projeto foi desenvolvido pelos gestores e endossado pela diretoria para mitigar as ações 
identificadas com maior NPR e maior gravidade.

A Entrevistada 2 comentou que a análise dos contextos interno e externo está documentada na empresa e abordou a contribuição dos resultados:

\begin{abstract}
Criamos uma instrução de trabalho, onde definimos os aspectos internos e externos, servindo como base para nos orientar onde se enquadrava cada tipo de riscos, no ambiente interno ou ambiente externo. A contribuição deste processo todo foi que paramos pra pensar nos riscos envolvidos em cada processo e podemos ver o quanto isso poderia impactar no nosso trabalho, se estes riscos acontecessem.
\end{abstract}

A Entrevistada 3 relatou como ocorreu a classificação dos fatores e da importância da análise dos cenários, "os fatores internos e externos foram identificados e listados, através de reuniões com os gestores, posteriormente se utilizou a matriz SWOT para fazer a classificação dos mesmos" [...]. O Entrevistado 4 acrescentou que as análises dos contextos ocorrem de acordo com a relevância aos propósitos da organização:

\begin{abstract}
Os fatores externos e internos são avaliados em reunião de diretrizes estratégicas, onde o grupo gestor identifica as questões importantes e que sejam pertinentes aos propósitos da organização. Foi criada uma instrução de trabalho que contém os conceitos dos principais ambientes externos e internos para facilitar a identificação das questões externas e internas. Após a identificação das questões internas e externas as mesmas são posicionadas em uma matriz SWOT, para que seja feita uma qualificação destas questões e posteriormente uma gestão de riscos e oportunidades com a emissão de planos de ação.
\end{abstract}

Durante o processo de trabalho de uma empresa, os riscos são causados, principalmente, por fatores organizacionais e humanos (KEERS; VAN FENEMA, 2018).

\title{
4.6 Framework que fundamentou a gestão de riscos
}

Buscou-se responder de que forma se deu o processo de estruturação da gestão de riscos, identificar se foi adotada uma metodologia e se esta gestão foi formalizada na organização para evidenciar o comprometimento com este processo.

Nas entrevistas, os respondentes comentaram que não foi utilizada uma metodologia específica, porém o processo estruturado possui partes da ISO 31000 (ABNT ISO 31000, 2009). Foi identificado que existe uma metodologia e que esta está formalizada dentro da organização. A Entrevistada 1 falou: “As normativas COSO e IBGC (Instituto Brasileiro de Governança Corporativa) são abrangentes, modelos mais corporativos, enquanto a ISO 31000 é específica e adequada a todos os tipos de modelo de empresa; foi a que utilizamos". 
A Entrevistada 3 relatou: "Foi tomada como base a ISO 31000, sendo que essa se relaciona diretamente com a versão da ISO 9001:2015”. Esta que gerou a primeira necessidade de implantação da área de Gestão de Riscos. Por fim, o Entrevistado 4 corroborou com a afirmação dos demais, dizendo: "Foi estruturado um processo interno que segue algumas metodologias já consolidadas (parte da ISO 31000)”.

O uso da ISO 31000 refere-se como uma diretriz alternativa para o gerenciamento de riscos (DIAS, 2017). A estrutura organizacional atualizada melhora a estrutura anterior do COSO, reconhece o impacto da cultura e estratégia nas práticas da gestão de risco e, principalmente, concentra-se na criação, preservação e realização de valor (WRIGHT, 2018).

\subsection{Tratativa dos riscos e comunicação}

Esta fase teve o propósito de extrair dos entrevistados se a gestão de riscos da empresa contemplou as fases fundamentais recomendadas nos modelos apresentados no referencial teórico deste trabalho, que são: mapeamento, avaliação, mensuração, tratamento, monitoramento e comunicação. Todos os frameworks apresentados sugerem essas etapas em sua metodologia para gestão dos riscos e consideram essas fases fundamentais para o sucesso do processo e para os resultados da organização (BRASILIANO, 2016).

Ficou claro nas entrevistas que a empresa criou uma metodologia específica de acordo com suas particularidades e, com base na ISO 31000, percebe-se nos relatos dos entrevistados que esse processo norteou as fases recomendadas pelas metodologias consolidadas. Foram analisados trechos das entrevistas dos Entrevistados 2, 3 e 4, que, respectivamente, falaram:

\footnotetext{
A avaliação e a mensuração dos riscos são levantadas por cada área, onde são levantados os impactos, quantificando sob três aspectos: gravidade, urgência e tendência. Os riscos com maior gravidade e também, aqueles em que a soma do NPR for igual ou maior que 27 são tratados e definidas ações pertinentes à mitigação dos mesmos. O relatório de análise de riscos aborda três fatores principais, sendo: partes interessadas, processo e ambiente afetado. [...] Todas as normativas de cada setor são estudadas, avaliadas e validadas. [...] Foi definido um método de avaliação na própria planilha de análise de riscos avaliando qualitativamente e quantitativamente [...].
}

O papel da área de gestão de riscos é identificar os riscos, classificá-los conforme sua importância, criar ações para tratar e monitorar os riscos. Posteriormente a isso monitorar as datas de implantação das ações propostas e a eficácia das mesmas [...] As decisões são tomadas em consenso com o grupo e aprovação e apoio da 
direção. [...] Essas regras e políticas sobre o que e quando os riscos devem gerar planos de ações e como essas deverão ser monitoradas, estão estabelecidas em um procedimento interno do sistema de gestão Metaltecss [...] A avaliação dos riscos é feita de forma qualitativa e quantitativa: na qualitativa são avaliados o quanto o risco de descumprimento contratual de clientes, violação de regulamentos (ex: legislação ambiental), nome da empresa ficar relacionado a algo que a desonere no mercado e custo financeiro para correção desses fatores, caso venham ocorrer.[...] São elaborados planos de ações relativamente estruturados, seguindo a metodologia $5 \mathrm{~W} 2 \mathrm{H}$.

Os riscos são classificados seguindo algumas metodologias definidas internamente, como por exemplo: qualitativamente, deve ser gerado um plano para mitigação do risco se o impacto do risco for considerado grave afetando a capacidade de atender o cliente, não atender regulamentações governamentais, impactar na reputação da empresa ou gerar custos e quantitativamente do mesmo modo. É acrescentada uma avaliação, que vai levar em consideração também a urgência em mitigar o risco, como também a tendência de a fonte do risco permanecer ou até mesmo aumentar. São elaborados planos de ação estruturados tipo 5W2H que incluem atividades, responsáveis, prazos, recursos e análise da eficácia da ação implementada [...].

Os relatórios anuais das empresas fornecem pouca informação sobre riscos e outras questões que permitem aos investidores decisões informadas sobre o futuro (GULKO et al., 2017). O pensamento integrado e a gestão de riscos é viável e pode facilitar alternativas e novas ideias para melhorar a eficácia do gerenciamento de riscos e das partes interessadas (XIA et al., 2018). Na subseção seguinte serão apresentados os resultados através do software Nvivo 11® para desenvolver a análise de conteúdo proposta na metodologia.

\subsection{Análise com Auxílio do Software Nvivo 11®}

Nesta parte da análise, foram importadas para o software Nvivo $11 \circledR$ as quatro entrevistas obtidas junto aos gestores da empresa estudada. Esse material considera as fontes que possuem os dados para análise e exploração da pesquisa. Para isso, foi realizada a codificação dos nós. As referências mencionadas são as quantidades de vezes em trecho da entrevista ao qual foi atribuído algum código. Essa relação está demonstrada no Quadro 1.

Quadro 1 - Estrutura de nós obtidas do software Nvivo $11 \circledR$

\begin{tabular}{|l|c|c|}
\hline \multicolumn{1}{|c|}{ Nome } & Fontes & Referências \\
\hline Importância & 4 & 4 \\
\hline Aspectos motivadores & 3 & 4 \\
\hline Definição de riscos & 4 & 4 \\
\hline Linguagem comum & 0 & 0 \\
\hline Formalização & 3 & 3 \\
\hline Classificação & 4 & 10 \\
\hline Quantitativo e Qualitativo & 3 & 6 \\
\hline Ambientes interno e externo & 3 & 9 \\
\hline Responsabilidades & 4 & 14 \\
\hline
\end{tabular}




\begin{tabular}{|l|c|c|}
\hline Estratégico & 3 & 7 \\
\hline Objetivos & 3 & 6 \\
\hline Estruturação & 3 & 5 \\
\hline Metodologia & 4 & 4 \\
\hline Processos & 3 & 3 \\
\hline Ações & 4 & 16 \\
\hline Mudanças & 3 & 3 \\
\hline Comunicação & 1 & 1 \\
\hline
\end{tabular}

Fonte: Extraído do software Nvivo11® (2018).

Depois de criada a estrutura de nós e codificados os trechos das fontes (entrevistas) para cada nó relacionado, foi aplicada a teoria fundamentada de Flick (2009), que compreende as três etapas de codificação, que são: codificação aberta, codificação axial e codificação seletiva. Na codificação aberta, são formadas as categorias; na codificação axial, faz-se o aperfeiçoamento das mesmas resultando em subcategorias, sendo que estas foram resultantes da estrutura de nós criada no software Nvivo11®; já na codificação seletiva, foram feitas a associação dos elementos da subcategoria para construir a história do caso estudado.

$\mathrm{Na}$ codificação aberta, foram criadas as categorias que visaram a responder aos objetivos específicos desta pesquisa, e foram codificadas com as informações obtidas nas entrevistas. As categorias: importância, linguagem comum, classificação, direcionamento estratégico e estruturação, para as quais foram codificados através de nós, com base nas informações de cada entrevistado.

Para a codificação axial, foram identificadas as subcategorias inseridas em cada nó dentro das categorias na codificação aberta. Para o nó importância, foram determinadas as subcategorias aspectos motivadores e definição de riscos; na categoria linguagem comum surgiu a subcategoria formalização; para a categoria classificação, foram criadas as subcategorias (qualitativo e quantitativo, ambientes interno e externo, responsabilidades); dentro da categoria direcionamento estratégico, emergiu a subcategoria objetivos; e, por fim, por meio da categoria estruturação, as subcategoria identificadas foram metodologia, macroprocessos, ações, mudança, comunicação. O Quadro 2 ilustra as codificações.

Quadro 2 - Codificação teórica

\begin{tabular}{|c|c|c|}
\hline Codificação Aberta & Codificação Axial & Codificação Seletiva \\
\hline Importância & Importância & \multirow{4}{*}{$\begin{array}{l}\text { O presente trabalho trata da importância } \\
\text { da gestão de riscos. Na pesquisa } \\
\text { realizada, buscou-se saber quais foram } \\
\text { os aspectos motivadores para adotar o } \\
\text { sistema e como era a definição de riscos }\end{array}$} \\
\hline Aspectos motivadores & Aspectos motivadores & \\
\hline Definição de riscos & Definição de riscos & \\
\hline Linguagem comum & Linguagem comum & \\
\hline
\end{tabular}




\begin{tabular}{|c|c|c|}
\hline Formalização & Formalização & \multirow{13}{*}{$\begin{array}{l}\text { na organização. Os principais modelos } \\
\text { para implementação de gestão de riscos } \\
\text { abordam a necessidade de haver } \\
\text { formalização desse sistema para que haja } \\
\text { uma linguagem comum sobre os riscos } \\
\text { nas empresas. O processo compreende a } \\
\text { classificação dos riscos, que pode ser } \\
\text { qualitativo e quantitativo, sendo parte da } \\
\text { análise dos ambientes internos e } \\
\text { externos, cobertos pelo plano estratégico, } \\
\text { garantindo o atendimento dos objetivos } \\
\text { da organização. A estrutura deve ser } \\
\text { baseada em uma metodologia } \\
\text { consolidada e que faça parte de todos os } \\
\text { processos da organização com definição } \\
\text { de responsabilidades, ações para mitigar } \\
\text { riscos, um controle de mudanças e um } \\
\text { processo de comunicação eficaz. }\end{array}$} \\
\hline Classificação & Classificação & \\
\hline Quantitativo e Qualitativo & Quantitativo e Qualitativo & \\
\hline Ambientes interno e externo & Ambientes interno e externo & \\
\hline Responsabilidades & Responsabilidades & \\
\hline Estratégico & Estratégico & \\
\hline Objetivos & Objetivos & \\
\hline Estrutura & Estrutura & \\
\hline Metodologia & Metodologia & \\
\hline Processos & Processos & \\
\hline Ações & Ações & \\
\hline Mudanças & Mudanças & \\
\hline Comunicação & Comunicação & \\
\hline
\end{tabular}

Fonte: Elaborado pelos autores (2018), de acordo com a codificação teórica de Flick (2009).

Através do software Nvivo 11®, foi possível estabelecer relações a partir da codificação realizada com as fontes utilizadas na análise. Foi aplicado o recurso para consulta de frequência de palavras, que realiza a contagem dos termos mais significativos nos nós atribuídos, possibilitando verificar se as palavras mais citadas durante as entrevistas possuem relação com o objetivo da pesquisa.

Nesta análise, destacam-se as quatro palavras mais citadas (riscos, empresa, gestão, processos) que se relacionam diretamente com os objetivos geral e específicos desse trabalho. Outro recurso utilizado para fazer a análise de conteúdo, foi o cluster de palavras, ilustrado na Figura 1, a partir do qual foi possível verificar a relação textual conforme análise das referências codificadas em nós, fazendo o agrupamento das variáveis em comum.

A relação mais importante gerada no diagrama, ao qual se vinculou aos demais grupos, gerou uma ligação dos termos: objetivos, estratégico, oportunidade e externos. Essa ligação refere-se à integração da gestão de riscos aos objetivos estratégicos da organização, onde são aplicados controles para que efeitos indesejáveis não afetem os resultados pretendidos. Os fatores externos são avaliados buscando entender os riscos que esse ambiente pode trazer para os negócios bem como as oportunidades. Neste sentido, Lopes (2016) aborda a necessidade de integrar controles aos riscos, internos e externos, sejam estes riscos negativos, bem como os de oportunidades que são identificados no plano estratégico.

A ligação entre processos, sistema, direção, gestão e qualidade, remete ao sistema de gestão que a empresa possui para gerir seus riscos e que este processo é apoiado pela direção e o sistema de gestão de qualidade, conforme foi demonstrado na análise de discurso. Em 
relação a essa ligação, a ABNT ISO 31000 (2009) traz que a gestão de riscos deve estar intrínseca às demais atividades e processos da organização, e que esse processo faz parte das responsabilidades da administração.

Outra ligação encontrada foi entre empresa, riscos, classificação, gestores, responsáveis, planos e ação, que se refere à estrutura de gerenciamento de riscos da empresa, onde, os riscos recebem uma classificação, e os gestores são responsáveis pelos planos de ação para mitigação dos mesmos, visando minimizar ou reduzir perdas (BRASILIANO, 2016). Segue a Figura 1 com o Cluster de palavras.

Figura $1-$ Cluster de palavras

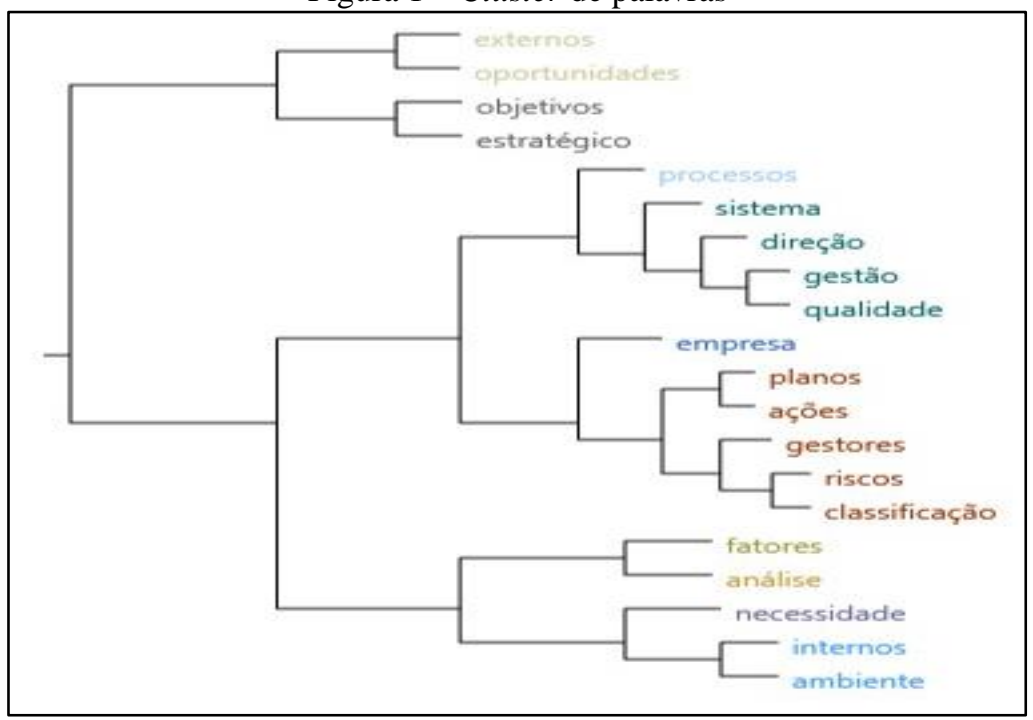

Fonte: Extraída do software Nvivo11® (2018).

Essa pesquisa gerou também uma relação entre os termos fatores e análise, que se refere à análise de fatores que possam afetar os resultados da organização, onde são identificadas questões importantes que sejam pertinentes aos propósitos da organização. Ainda nesta relação, os termos necessidade, internos e ambiente tratam da necessidade de se avaliar os riscos no ambiente interno da organização, identificando os pontos fracos que podem se tornar riscos potenciais para o negócio, onde estes devem ser cobertos pelo plano de gestão de riscos da organização.

Através dos resultados com a utilização do recurso de cluster de palavras, foi possível obter uma visão abrangente da integração dos termos mais falados nas entrevistas semiestruturadas, proporcionando a compreensão dos objetivos da pesquisa. 


\section{Considerações Finais}

Em resposta ao objetivo do artigo, constatou-se que a empresa possui um processo de gerenciamento de riscos e que este faz parte das rotinas administrativas da empresa. Neste sentido, com a análise da bibliografia sobre o tema e dos dados obtidos com a aplicação da metodologia proposta, foi possível alcançar o objetivo apresentado.

O estudo buscou identificar como foi estruturada a gestão de riscos na empresa. Esse propósito foi compreendido no método, através das análises de conteúdo onde os entrevistados relataram que a empresa adotou um sistema próprio, de acordo com suas particularidades, mas que contemplaram as principais fases (mapeamento, avaliação, mensuração, tratamento, monitoramento e comunicação) para gerenciar riscos fazem parte do sistema na empresa, conforme determinados nas metodologias abordadas na revisão da literatura.

Com a implementação da gestão de riscos na empresa, identificou-se mudanças na gestão da organização, que adotou uma postura mais preventiva e estratégica para evitar perdas. Neste sentido, também foi evidenciada uma mudança na cultura organizacional, onde todos os gestores foram envolvidos no processo e desenvolvimento da gestão de riscos, atribuindo responsabilidades de pessoas de todos os processos.

A empresa teve que reestruturar sua antiga gestão para inserir o pensamento baseado em riscos e alinhar aos objetivos estratégicos do negócio. Esse processo gerou impacto na estrutura organizacional, necessitando maiores responsabilidades de todo grupo gestor. Com as análises dos riscos envolvendo as partes interessadas e os ambientes internos e externos, originaram-se ações com investimentos, ocasionando um impacto financeiro preventivo.

De maneira geral, através dos dados obtidos com a realização da pesquisa, é possível compreender que a empresa estudada demonstra um alinhamento com as diretrizes sugeridas nas metodologias de gestão de riscos. Com esse estudo, destaca-se a relevância do tema, visto que a gestão de riscos pode ser uma aliada na prevenção de perdas, dada a necessidade de as empresas estarem cada vez mais preparadas para competir em um mercado cada vez mais oscilante e imprevisível.

Considerando as limitações da pesquisa realizada, pode ser destacado o fato do tema ainda ser mais abrangente em empresas financeiras, sendo pouco explorado como ferramenta complementar no contexto da gestão para qualquer tipo de empresa. Neste sentido, também foi percebida a falta de diversidade de cases de implementação de gestão de riscos como 
prática estratégica, compreendendo o uso de frameworks, dado que tais modelos para gerenciar riscos são relativamente novos.

Por fim, para pesquisas futuras, sugere-se explorar como a gestão de riscos pode contribuir para melhorar o planejamento estratégico das organizações, por meio de mensuração, visto que esta ferramenta, alinhada aos objetivos propostos no direcionamento estratégico, facilita a identificação de potenciais riscos que possam impedir que os resultados pretendidos sejam alcançados.

\section{Referências}

ANDERSON, D. COSO ERM: Getting risk management right: Strategy and organizational performance are the heart of the updated framework. Internal Auditor, v. 74, n. 5, p. 3843, 2017.

ASSOCIAÇÃO BRASILEIRA DE NORMAS TÉCNICAS. ABNT ISO 9001: Sistema de Gestão da Qualidade Requisitos. 3 ed. Rio de Janeiro: ABNT, 2015.

ABNT NBR ISO 31000: Gestão de Riscos Princípios e Diretrizes. 1 ed. Rio de Janeiro: ABNT, p. 24, 2009.

BARALDI, P. Gerenciamento de riscos empresariais. 3. ed. Rio de Janeiro: Camus, p. 345, 2010.

BERGAMINI, S. Controles Internos como um Instrumento de Governança

Corporativa. Revista do Bndes, Rio de Janeiro, v. 12, n. 24, p.149-188, dez. 2005.

Disponível em:

<http://www.bndes.gov.br/SiteBNDES/export/sites/default/bndes_pt/Galerias/Arquivos/co nhecimento/revista/rev2406.pdf>. Acesso em: 05 maio 2017.

BRASILIANO, A. C. R. Inteligência em riscos: Gestão Integrada em Riscos Corporativos. São Paulo: Sicurezza, p. 248, 2016.

CHOO, B. S.-Y.; GOH, J. C.-L. Pragmatic adaptation of the ISO 31000: 2009 enterprise risk management framework in a high-tech organization using Six Sigma. International Journal of Accounting \& Information Management, v. 23, n. 4, p. 364-382, 2015.

COSO. Emtreprise risk management-integrated framework. Committee of Sponsoring Organizations of the Treadway Commission, 2013.

DIAS, A. A. de S. P. A more effective audit after COSO ERM 2017 or after ISO 31000: 2009? Revista Perspectiva Empresarial, v. 4, n. 2, p. 73-82, 2017.

FERRO, D. dos S. Gestão de riscos corporativos: um estudo multicaso sobre seus métodos e técnicas. 2015. Dissertação (Mestrado em Administração) - Faculdade de Economia, Administração e Contabilidade, Universidade de São Paulo, São Paulo, 2015. 
Disponível em: <http://www.teses.usp.br/teses/disponiveis/12/12139/tde-19012016150607/>. Acesso em: 12 abr. 2017.

FLICK, U.; GIBBS, G. Análise de dados qualitativos. Porto Alegre: Bookman, p. 196, 2009.

FONSECA, L. M. From Quality Gurus and TQM to ISO 9001: 2015: a review of several quality paths. International Journal for Quality Research (IJQR), v. 9, n. 1, p. 167-180, 2015.

GIL, A. C. Como elaborar projetos de pesquisa. 5. ed. São Paulo: Atlas S.A., p. 184, 2010.

GULKO, N.; HYDE, C.; SEPPALA, N. Disclosure of corporate risks and governance before, during and after the global financial crisis: case study in the UK construction industry in 2006-2009. International Journal of Disclosure and Governance, v. 14, n. 3, p. 207-223, 2017.

KAYA, İ. Perspectives on Internal Control and Enterprise Risk Management. In: Eurasian Business Perspectives. Springer, Cham, p. 379-389, 2018.

KEERS, B. B. M.; VAN FENEMA, P. C. Managing risks in public-private partnership formation projects. International Journal of Project Management, v. 36, n. 6, p. 861$875,2018$.

LOPES, A. C. S. Gestão De Risco: A importância da resiliência em eventos indesejáveis. 2016. 119 f. Dissertação (Mestrado) - Curso de Administração, Gestão Socioambiental e da Saúde, Fundação Getulio Vargas, São Paulo, 2016. Disponível em: $<$ http://bibliotecadigital.fgv.br/dspace/bitstream/handle/10438/16669/Lopes, A.C.S (2016) - Gestão de risco_a importância da resiliência em eventos indesejáveis.pdf?sequence=3\&isAllowed=y>. Acesso em: 04 abr. 2017.

MASSAINI, S. A.; DE OLIVEIRA, V. R. F.; OLIVA, F. L. Identification of Corporate Risks not Environmental of Value of Private Higher Education Institutions. Management in Dialogue Review, v. 19, n. 1, p. 89-111, 2017.

MEDIĆ, S.; KARLOVIĆ, B.; CINDRIĆ, Z. New standard ISO 9001: 2015 and its effect on organisations. Interdisciplinary Description of Complex Systems: INDECS, v. 14, n. 2, p. 188-193, 2016.

OLECHOWSKI, A. et al. The professionalization of risk management: What role can the ISO 31000 risk management principles play? International Journal of Project Management, v. 34, n. 8, p. 1568-1578, 2016.

PRADO, E. V. do et al. Gerenciamento de riscos corporativos em empresas com atuação internacional. Perspectivas contemporâneas: Revista eletrônica de ciências sociais aplicadas, Campo Mourão, v. 2, n. 9, p.210-228, 30 dez. 2014. Disponível em: $<$ http://revista.grupointegrado.br/revista/index.php/perspectivascontemporaneas >. Acesso em: 22 jun. 2017. 
WRIGHT, C. the CAE-CRO relationship: Chief audit executives and chief risk officers can collaborate in many ways to ensure the organization manages risks effectively. Internal Auditor, v. 75, n. 1, p. 31-36, 2018.

XIA, N. et al. Towards integrating construction risk management and stakeholder management: A systematic literature review and future research agendas. International Journal of Project Management, v. 36, n. 5, p. 701-715, 2018.

YIN, R. K. Estudo de caso: Planejamento e Métodos. Tradução de Cristhian Matheus Herrera. 5. ed. Porto Alegre: Bookman, 2015. 